\title{
ANALISIS PENGARUH USAHA KERAJINAN SERABUT KELAPA DENGAN PENINGKATAN EKONOMI MASYARAKAT DUSUN BENYER DESA TELAGA WARU KECAMATAN PRINGGABAYA KABUPATEN LOMBOK TIMUR
}

\author{
Agus Riswanto ${ }^{1}$, Eliyani Nirwana ${ }^{2}$, \\ ${ }^{1}$ Prodi Pendidikan Ekonomi FKIP Universitas Hamzanwadi \\ email: agusriswanto@gmail.com \\ ${ }^{2}$ Prodi Pendidikan Ekonomi FKIP Universitas Hamzanwadi \\ email: eliyani.nirwana@gmail.com
}

\begin{abstract}
ABSTRAK
Penelitian ini bertujuan untuk mengetahui apakah ada korelasi antara usaha kerajinan serabut kelapa dengan peninghkatan ekonomi masyarakat. Jenis penelitian ini menggunakan penelitian kuantitatif . Populasi dalam penelitian ini adalah seluruh pengerajin sapu serabut kelapa di Dusun Benyer Desa Telaga Waru. Sementara untuk teknik penggambilan sampel menggunakan teknik probability sampling dengan simple random sampling. Dalam pengumpulan data menggunakan teknik dokumentasi, observasi dan angket/kuesioner. Teknik analisis data dengan menggunakan uji validitas dan uji reliabilitas, uji normalitas, analisis korelasi, uji koefisien determinasi serta uji hipotesis. Berdasarkan teknik analisis data trersebut, berdasarkan uji validitas dan reliabilitas menunjukkan bahwa semua item pertanyaan pada variabel $\mathrm{X}$ dan variabel $\mathrm{Y}$ adalah valid dan reliabel karena nilai $\mathrm{r}_{\text {hitung }}$ lebih besar dari nilai $\mathrm{r}_{\text {tabel }}$ $\left(r_{\text {hitung }}>r_{\text {tabel }}\right)$. Dan pada uji normalitas menunjukkan bahwa semua data berdistribusi normal. Pada uji korelasi menunjukkan bahwa variabel X (usaha kerajinan sapu serabut kelapa) memiliki korelasi yang sinifikan dengan variabel $\mathrm{Y}$ (Peningkatan ekonomi masyarakat) karena nilai $\mathrm{r}_{\text {hitung }}$ lebih besar dari nilai $\mathrm{r}_{\text {tabel }}(0,244>0,207)$. Dan pada uji koefisien determinasi menunjukkan bahwa sebesar korelasi antara usaha kerajinan sapu serabut kelapa dengan peningkatan ekonomi masyarakat sebesar $6 \%$ dan sisanya dipengaruhi oleh factor lain yang tidak diteliti dalam penelitian ini. Sedangkan pada uji hipotesis dengan menggunakan uji $t$ menghasilkan nilai $t_{\text {hitung }}$ lebih besar dari nilai $t_{\text {tabel }}(2,331>$ 1,6623) dan nilai Signifikan lebih kecil dari nilai signifikan yang sudah ditentukan yaitu $0,05(0.02<0,05)$, maka dapat dinyatakan bahwa $\mathrm{H}_{\mathrm{o}}$ ditolak dan $\mathrm{H}_{\mathrm{a}}$ diterima, artinya signifikan. Sehingga dapat disimpulkan bahwa dari hasil pengujian hipotesis tersebut terbukti "Ada korelasi yang signifikan antara Usaha kerajinan sapu serabut kelapa dengan peningkatan ekonomi masyarakat di dusun Benyer Desa Telaga Waru Kecamatan Pringgabaya Kabupaten Lombok Timur".
\end{abstract}

Kata Kunci : Usaha kerajinan serabut kelapa, ekonomi masyarakat 


\begin{abstract}
Correlation between coconut fiber handicraft business and economic improvement of Benyer village Telaga Waru Pringgabaya District, East Lombok regency.
\end{abstract}

This study aims to determine whether there is a correlation between coconut fiber handicraft business with the improvement of the community's economy. This type of research uses quantitative research. The population in this research is all coconut fiber broom craftsman in Benyer Village Telaga Waru Village. While for the technique of sampling using technique probability sampling with simple random sampling. In collecting data using documentation technique, observation and questionnaire / questionnaire. Technique of data analysis by using validity test and reliability test, normality test, correlation analysis, coefficient of determination test and hypothesis test. Based on the technique of data analysis, based on validity and reliability test indicate that all item of question on variable $\mathrm{X}$ and variable $\mathrm{Y}$ is valid and reliable because the value of $r_{\text {value }}$ is bigger than $r_{\text {table }}$ value $\left(r_{\text {value }}>r_{\text {table }}\right)$. and on the normality test shows that all data is normally distributed. In the correlation test showed that the variable $\mathrm{X}$ (coconut fiber broom handling business) has a significant correlation with variable $\mathrm{Y}$ (economic improvement of society) because the value of $r_{\text {value }}$ is bigger than $r_{\text {table }}$ value $(0,244>0,207)$. And on the coefficient of determination test showed that as big as correlation between coconut fiber broom handicraft business with society economic improvement equal to $6 \%$ and the rest influenced by other factor not examined in this research. While on hypothesis test by using $t$ test yield $t_{\text {value }}$ bigger than $t_{\text {table }}$ value $(2,331>1,6623)$ and significance value smaller than predetermined significant value that is 0,05 $(0.02<0,05)$, hence can be stated that Ho is rejected and Ha accepted, meaning significant. So it can be concluded that the results of testing the hypothesis proved "There is a significant correlation between coconut fiber broom business with the economic improvement of the community in the hamlet Benyer Telaga Waru Village Pringgabaya District East Lombok regency".

Keywords : Coconut fiber handicraft business, community economy

\title{
PENDAHULUAN
}

Indonesia adalah bangsa yang heterogen, baik dari segi sumber daya manusia dan sumber daya alamnya. Terlepas dari fenomena politik, ekonomi dan sosial yang terbangun saat ini, Pulau-pulau terpencil dan daerah pedalaman juga menjadi bagian penting yang tidak terlepaskan dari keutuhan kedaulatan NKRI serta menjadi harapan tumpuan kekuatan kedaulatan bangsa. Namun dalam kenyataannya, kekuatan politik dan letak geografis sangat berpengaruh terhadap kemajuan daerah-daerah dalam kerangka Otonomi Daerah NKRI. (Antonius, 2011: 20). Di Indonesia, ekonomi kreatif merupakan sebuah konsep baru yang mengintensifkan informasi dan kreativitas dengan mengandalkan ide dan 
pengetahuan dari sumber daya manusia sebagai faktor produksi mulai diakui dan memiliki peran yang sangat strategis dalam pembangunan ekonomi dan pengembangan bisnis. Dalam tiga terakhir ini istilah ekonomi kreatif dan industri kreatif mulai banyak dibicarakan. Terlebih ketika Menteri sosial Republik Indonesia menyebutkan tentang pentingnya memberdayakan dan mengembangkan Usaha ekonomi kreatif dengan memperhatikan segala potensi yang ada terutama untuk kalangan ekonomi kebawah sebagai kelompok penyandang masalah kesejahteraan sosial.

Desa Telaga Waru terletak di Kecamatan Pringgabaya, Kabupaten Lombok Timur, Provinsi Nusa Tenggara Barat. Pada awal berdirinya Desa Telaga Waru merupakan Desa Pemekaran dari Desa Bagikpapan pada tahun 2012 berdasarkan Peraturan Daerah No. 4 Tahun 2012, hal ini didasari oleh semangat perubahan untuk melakukan pemberdayaan dan pembinaan kepada masyarakat dengan harapan terjadi pemerataan pembangunan. Dan ini selaras dengan harapan pemerintah kabupaten Lombok Timur untuk melakukan program Pemekaran Desa di Wilayah Kabupaten Lombok Timur.

Kerajinan Sapu Serabut Kelapa merupakan salah satu dari beraneka ragam kerajinan tradisional Indonesia terutama Lombok Timur yang patut di kembangkan. Kerajinan Sapu Serabut Kelapa bahan bakunya berasal dari Serabut Kelapa yang direndam kemudian dihaluskan lalu dijemur dan diproduksi menjadi sapu. Kerajinan Sapu serabut kelapa ini tersebar luas tidak saja diwilayah Nusa Tenggara Barat bahkan sampai di luar Wilayah Nusa Tenggara Barat. Kerajinan Sapu serabut Kelapa ini dimulai sejak tahun 1980-an oleh Bapak Badarudin (Alm) yang merupakan penduduk asli Benyer, selaku penggagas dan karena ide kreatifnya mampu memberdayakan penduduk setempat dengan memberikan ilmu keterampilannya sehingga mampu memberikan pekerjaan sampingan dan membantu perekonomian masyarakat sampai saat ini.

Dengan demikian ada Dua Dusun yang penduduknya mayoritas sebagai pengerajin sapu serabut kelapa, karena dapat membantu meningkatkan ekonomi masyarakat setempat. Dalam membuat kerajinan sapu serabut kelapa ini tidak terikat oleh kontrak atau perjanjian kerja, sehingga pekerjaan ini dapat dilakukan 
kapan saja dan dapat dikerjakan dimana saja. Para pengrajin memperoleh penghasilan berdasarkan jumlah bahan yang diproduksi. Misalnya 300 Bungkul Serabut kelapa, akan menghasilkan sapu sebanyak 220 buah dengan harga perbuah sebesar Rp. 5.000,-. Sehingga hasil yang didapat dalam satu produksi atau sekitar 1,5 Bulan setelah dikurangi biaya produksi sebesar Rp. 750.000,-. Jadi pendapatan perbulan para pengerajin sapu serabut kelapa rata-rata berkisar sebesar Rp. 500.000, bahkan bisa lebih jika bahan produksi semakin besar. Namun penghasilan pengrajin tersebut tidak stabil karena bahan baku dari kerajinan tersebut terkadang sulit diperoleh salah satunya adalah kayu pegangan, hal ini disebabkan oleh faktor ketersediaan dan jarak tempuh.

\section{METODE PENELITIAN}

Populasi adalah wilayah generalisasi yang terdiri atas objek atau subjek yang mempunyai kualitas dan karakteristik tertentu yang ditetapkan oleh peneliti untuk dipelajari dan kemudian ditarik kesimpuannya”. Berdasarkan pengertian tersebut diatas, maka yang menjadi populasi dalam penelitian ini adalah sebanyak 619 Keluarga Pengerajin Sapu Serabut Kelapa, diantaranya terdiri dari 382 Keluarga dari Dusun Benyer Daya dan 237 Keluarga dari Dusun Benyer Lauq.

"Sampel adalah bagian dari jumlah dan karakteristik yang dimiliki oleh populasi tersebut. Apa yang dipelajari dari sampel itu, kesimpulannya akan dapat diberlakukan untuk populasi. Untuk itu sampel yang diambil dari populasi harus betul-betul representative (Mewakili)" Teknik pengambilan sampel yang digunakan dalam penelitian ini dengan teknik Probability sampling dengan jenis Simple random sampling. "Simple random sampling yaitu carapengambilan sampel dari anggota populasi dengan menggunakan acak tanpa memperhatikan strata (tingkatan) dalam anggota populasi tersebut" (Riduwan, 2009:58). Dalam penelitian ini, untuk melakukan pengumpulan data dengan menggunakan beberapa teknik, antara lain :

Teknik dokumentasi digunakan untuk mendapatkan data awal mengenai kegiatan usaha kerajinan sapu serabut kelapa dan Peningkatan ekonomi masyarakat yaitu berupa data jumlah Pengerajin Sapu serabut kelapa serta jumlah pendapatan 
pengerajin sapu serabut kelapa di Dusun Benyer Desa Telaga Waru Kecamatan Pringgabaya Kabupaten Lombok Timur.

Observasi adalah teknik pengumpulan data melalui pengamatan. Menurut Sugiyono (2009:226) "Observasi adalah dasar semua ilmu pengetahuan, dimana para ilmuan hanya dapat bekerja berdasarkan data yaitu fakta mengenai dunia kenyataan". Dengan melakukan observasi pada penelitian ini dapat mengamati objek penelitian dengan lebih cermat dan detail tentang Proses atau kegiatan usaha kerajinan sapu serabut kelapa serta dapat mengetahui peningkatan ekonomi masyarakat secara langsung

\section{HASIL PENELITIAN}

Pengumpulan data pada penelitian ini dilaksanakan dengan menggunakan Angket/Kuesioner. Dimana Angket/Kuesioner dibagikan kepada 88 responden yang merupakan pengerajin sapu serabut kelapa. Jumlah pertanyaan sebanyak 20 Item, terdiri dari 10 Item pertanyaan untuk Variabel $\mathrm{X}$ (Usaha kerajinan sapu serabut kelapa) dan 10 Item pertanyaan untuk variabel Y (Peningkatan ekonomi masyarakat).

Berikut Data Profil responden dan jawaban responden atas angket dalam penelitian ini adalah sebagai berikut :

\section{Tabel 1 Profil Responden berdasarkan Jenis Kelamin}

\begin{tabular}{|l|l|c|c|}
\hline \multirow{2}{*}{ Jenis Kelamin } & Laki-Laki & 32 Org & $36 \%$ \\
\cline { 2 - 4 } & Perempuan & 56 Org & $64 \%$ \\
\hline
\end{tabular}

Dari tabel 1 menunjukkan bahwa dari 88 Orang Responden, diantaranya 32 Orang atau sebesar 36\% responden adalah laki-laki, sementara 56 orang atau sebesar $64 \%$ adalah perempuan. Sehingga dengan demikian Perempuan lebih banyak dari laki-laki menjadi pengerajin sapu serabut kelapa.

Tabel 2. Profil Responden berdasarkan Usia/Umur

\begin{tabular}{|l|l|c|c|}
\hline \multirow{2}{*}{ Umur / Usia } & $16-45 \mathrm{Th}$ & 54 Orang & $61 \%$ \\
\cline { 2 - 4 } & 45 keatas & 34 Orang & $39 \%$ \\
\hline
\end{tabular}

Sumber : Data Primer 
Dari tabel 2 menunjukkan bahwa dari 88 Orang responden, sebanyak 54 orang atau sebesar 61\% merupakan usia antara 16-45 tahun, sementara 34 Orang atau sebesar 39 orang merupakan usia 45 Tahun ke atas. Dengan demikian usia 1645 Tahun merupakan usia terbanyak menjadi pengerajin sapu serabut kelapa di Dusun Benyer Desa Telaga Waru

Tabel 3. Profil Responden berdasarkan Pendidikan

\begin{tabular}{|l|l|c|c|}
\hline \multirow{3}{*}{ Pendidikan } & SD & 50 orang & $57 \%$ \\
\cline { 2 - 4 } & SLTP & 13 orang & $15 \%$ \\
\cline { 2 - 4 } & SLTA & 19 orang & $22 \%$ \\
\cline { 2 - 4 } & PT & 6 orang & $7 \%$ \\
\hline
\end{tabular}

Sumber : Data Primer

Dari tabel 3 menunjukkan bahwa dari 88 orang responden, sebanyak 50 Orang atau sebesar 57\% merupakan lulusan SD, 13 Orang atau sebesar 15\% merupakan lulusan SLTP, 19 orang atau sebesar 22\% merupakan lulusan SLTA, dan hanya 6 Orang atau sebesar 7\% merupakan lulusan Perguruan Tinggi. Dengan demikian lulusan SD lebih besar bahkan lebih dari 50\% menjadi pengerajin sapu serabut kelapa.

Tabel 4. Profil Responden berdasarkan Status

\begin{tabular}{|l|l|c|c|}
\hline \multirow{2}{*}{ Status } & Kawin & 71 Orang & $81 \%$ \\
\cline { 2 - 4 } & Janda / Duda & 17 Orang & $19 \%$ \\
\hline
\end{tabular}

Sumber : Data Primer

Dari tabel 4 menunjukkan bahwa dari 88 orang responden, sebanyak 71 orang atau sebesar $81 \%$ responden berstatus kawin, sementara Janda/Duda sebanyak 17 orang atau sebesar 19\%. Dengan demikian, pengerajin sapu serabut kelapa kebanyakan berstatus kawin.

Tabel 5. Profil Responden berdasarkan Jumlah Tanggungan

\begin{tabular}{|l|l|c|c|}
\hline \multirow{4}{*}{ Jumlah Tanggungan } & $0-1$ Orang & 20 orang & $23 \%$ \\
\cline { 2 - 4 } & $2-3$ Orang & 62 Orang & $70 \%$ \\
\cline { 2 - 4 } & 4 orang keatas & 6 Orang & $7 \%$ \\
\hline
\end{tabular}

Sumber : Data Primer 
Dari tabel 4.5 menunjukkan bahwa dari 88 orang responden, sebanyak 20 orang atau sebesar $23 \%$ memiliki tanggungan antara $0-1$ orang, dan 62 orang atau sebesar 70\% memiliki tanggungan 2-3 orang, sementara 6 orang atau sebesar 7\% memiliki tanggungan 4 orang keatas. Dengan demikian, jumlah tanggungan Pengerajin sapu serabut kelapa di Dusun Benyer Desa Telaga Waru antara 2-3 orang.

Tabel 6. Profil Responden berdasarkan pendapatan

\begin{tabular}{|l|l|c|c|}
\hline \multirow{4}{*}{ Pendapatan } & Kurang Rp. 1.000 .000 & 41 orang & $47 \%$ \\
\cline { 2 - 4 } & Rp. $1.000 .000-$ Rp. 2.000 .000 & 28 orang & $32 \%$ \\
\cline { 2 - 4 } & Rp. 2.000.000 - Rp. 3.000.000 & 12 orang & $14 \%$ \\
\cline { 2 - 4 } & Lebih Rp. 3.000.000 & 7 orang & $8 \%$ \\
\hline
\end{tabular}

Sumber : Data Primer

Dari tabel 6 menunjukkan bahwa dari 88 orang responden, sebanyak 41 orang atau sebesar 47\% memiliki pendapatan kurang dari Rp. 1.000.000, sebanyak 28 orang atau sebesar 32\% memiliki pendapatan antara Rp.1.000.000 - Rp. 2.000.000, dan sebanyak 12 orang atau sebesar $14 \%$ memiliki pendapatan antara Rp. 2.000.000 - Rp. 3.000.000, sementara 7 orang atau sebesar 8\% memiliki pendapatan lebih dari Rp. 3.000.000. dengan demikian Pendapatan Pengerajin sapu serabut kelapa masih lebih besar yang pendapatannya di bawah Rp. 1.000.000.

Tabel 7. Hasil uji reliabilitas

\begin{tabular}{|c|c|c|c|c|c|}
\hline No & Variabel & $\begin{array}{c}\text { Nilai } \\
\text { Cronbach's } \\
\text { Alpha }\end{array}$ & $\begin{array}{c}\mathrm{r}_{\text {tabel }} \\
(\text { Taraf } \\
\operatorname{sig} 5 \%)\end{array}$ & $\begin{array}{c}\text { Batas } \\
\text { Minimal } \\
\text { Cronbach } \\
\text { Alpha }\end{array}$ & Ket. \\
\hline 1 & $\begin{array}{c}\text { Kerajinan } \\
\text { Sapu (X) }\end{array}$ & 0,661 & 0,207 & 0,60 & Reliabel \\
\hline 2 & $\begin{array}{c}\text { Ekonomi } \\
\text { Masyarakat }\end{array}$ & 0,989 & 0,207 & 0,60 & Reliabel \\
\hline
\end{tabular}

Sumber : Hasil olahan SPSS 15.0

Berdasarkan hasil uji reliabilitas yang tersaji pada tabel 4.11 menunjukkan 
bahwa variabel usaha kerajinan sapu serabut kelapa (X) memiliki nilai Cronbach's Alpha sebesar 0,661 dan variabel Peningkatan ekonomi masyarakat (Y) memiliki nilai 0,989. Maka dapat dilihat, nilai Cronbach's Alpha lebih besar dari nilai batas minimum Cronbach's Alpha yaitu 0,60 atau nilai Cronbach's Alpha sebagai $\mathrm{r}_{\text {hitung }}$ lebih besar dari nilai $r_{\text {tabel }}$ sebesar 0,207 $\left(\left(r_{\text {hitung }}>r_{\text {tabel }}\right)\right.$. Dengan demikian seluruh pertanyaan pada masing-masing variabel dinyatakan reliabel sehingga dapat digunakan untuk pengumpulan data sebagai alat ukur.

Uji normalitas dalam penelitian ini digunakan untuk mengetahui apakah data memiliki sebaran yang normal. Untuk Uji Normalitas dalam hal ini menggunakan program SPSS 15.0 melalui gambar kurva histogram dan kurva p-p Plot untuk menunjukkan sebaran data penelitian. Data yang normal akan terlihat menyebar ke semua daerah kurva normal, sedangkan data yang tidak normal distribusinya akan berada di samping kiri dan kanan garis kurva normal.

Dari hasil Uji Normalitas data yang dihitung dengan bantuan program SPSS 15.0 diperoleh hasil uji normalitas data sebagai berikut :

Tabel 8. Uji Normalitas dengan Skewness dan Kurtosis

\begin{tabular}{|l|c|c|c|c|c|}
\hline & $\mathrm{N}$ & \multicolumn{2}{|c|}{ Skewness } & \multicolumn{2}{c|}{ Kurtosis } \\
\cline { 2 - 6 } & Statistic & Statistic & $\begin{array}{c}\text { Etd. } \\
\text { Error }\end{array}$ & Statistic & $\begin{array}{c}\text { Std. } \\
\text { Error }\end{array}$ \\
\hline $\begin{array}{l}\text { Unstandardized } \\
\text { Residual } \\
\text { Valid N (listwise) }\end{array}$ & 88 & 0.917 & 0.257 & 0.249 & 0.508 \\
\hline
\end{tabular}

Sumber : Hasil olahan SPSS 15.0

Dari tabel 8 menunjukkan bahwa nilai Sampel (N) sebesar 88, dimana rasio Skewness sebesar 0,917 dengan standar error sebesar 0,257 sehingga menjadi 3,5680, Sedangkan rasio Kurtosis sebesar 0,249 dengan standar error 0,508 sehingga menjadi 0,4901. Untuk mengetahui apakah data berdistribusi normal atau tidak dengan memahami kriteria pengujiannya yaitu apabila rasio Skewness dan Kurtosis berada diantara -2 hingga +2 , maka dapat disimpulkan bahwa distribusi data adalah normal. Dari hasil rasio Skewness dan rasio Kurtosis diatas dapat 
Riswanto, Nirwana. Analisis pengaruh Usaha Kerajinan Serabut Kelapa dengan Peniingkatan ekonomi...

diperoleh nilai yaitu nilai skewness sebesar 3,5680 dan nilai kurtosis sebesar 0,4901 yang berarti dalam batasan (range) antara -2 hingga +2 yang berarti data adalah berdistribusi normal. Selain itu, uji normalitas dapat pula ditunjukkan oleh gambar dari Kurva Histogram dan kurva normal p.p Plot of Regresion sebagai berikut

histogram

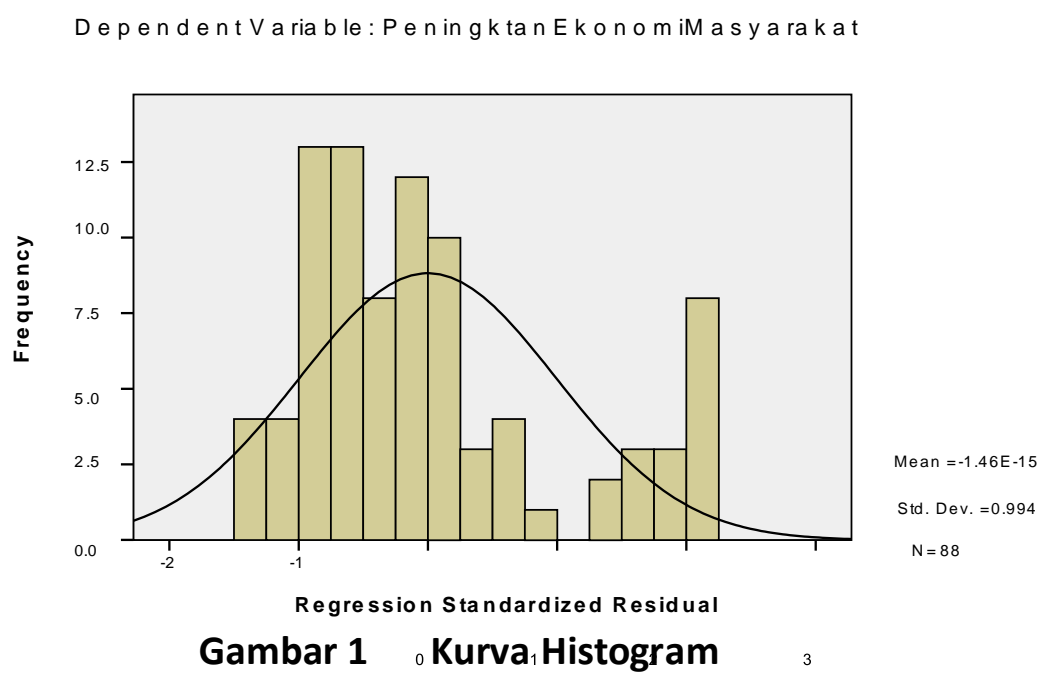

$\mathbf{N}$ orm al $\mathbf{P}$-P P lot of $\mathbf{R}$ egression $\mathbf{S}$ tandardized $\mathbf{R}$ esidual

D ependent V ariable: Peningkatan Ekonomi Masyarakat

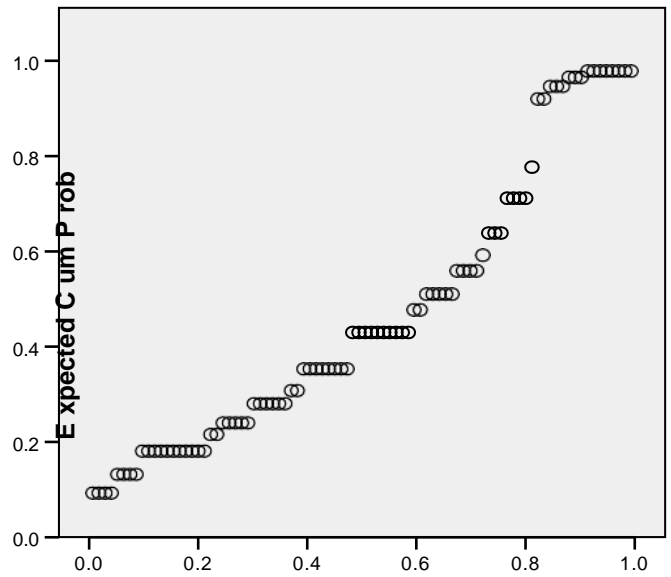

Gambar 2 Kurva porpspilotalef, Regosession

Dari gambar.1 dan gambar 2 diatas menunjukkan bahwa pada gambar 4.1 
(kurva Histogram), garis kurva tidak berada pada sampingkanan maupun samping kiri, akan tetapi tepat berada ditengah. Sedangkan pada gambar 4.2 ( kurva p-p Plot of Regression), garis diagonal dalam grafik tersebut menggambarkan keadaan ideal mengikuti garis distribusi normal. Titik-titik di sekitar garis adalah keadaan data yang diuji, dimana kebanyakan titik-titik berada sangat dekat dengan garis atau bahkan menempel pada garis. Berdasarkan hal tersebut, maka dapat disimpulkan bahwa data penelitian adalah berdistribusi normal. Analisis pengaruh digunakan untuk mengetahui derajat pengaruh dan kontribusi antara Usaha kerajinan sapu serabut kelapa terhadap peningkatan ekonomi masyarakat di Dusun Benyer Desa Telaga Waru. Dalam penelitian ini digunakan korelasi sederhana yaitu dengan teknik korelasi product moment. Dengan kriteria yaitu, 1). Bila nilai $\mathrm{r}=0$ atau mendekati 0 , maka hubungan antara kedua variabel sangat lemah atau tidak terdapat hubungan sama sekali. 2). Bilai nilai $r=+1$ atau mendekati 1, maka korelasi antara kedua variabel dikatakan positif dan sangat kuat. 3). Bila nilai $r=-1$ atau mendekati - 1, maka pengaruh antara kedua variabel dikatakan negative dan sangat kuat.

\section{SIMPULAN DAN SARAN}

Berdasarkan hasil penelitian dan pembahasan yang dilakukan tentang analisis pengaruh usaha kerajinan sapu serabut kelapa dengan peningkatan ekononomi masyarakat di Dusun Benyer Desa Telaga Waru Kecamatan Pringgabaya Kabupaten Lombok Timur, maka dapat disimpulkan sebagai berikut : (1) Hasil Uji Analisis pengaruh menunjukkan bahwa terdapat pengaruh antara usaha kerajinan sapu serabut kelapa dengan peningkatan ekonomi masyarakat. (2) Hasil Uji Hipotesis dengan menggunakan Uji t disimpulkan bahwa $\mathrm{H}_{\mathrm{o}}$ ditolak dan $\mathrm{H}_{\mathrm{a}}$ diterima, artinya Ada pengaruh yang signifikan antara usaha kerajinan sapu serabut kelapa dengan peningkatan ekonomi masyarakat di dusun Benyer Desa Telaga Waru Kecamatan Pringgabaya Kabupaten Lombok Timur.

Berdasarkan kesimpulan yang dikemukan diatas, maka penting kiranya penulis menyampaikan saran-saran sebagai bahan pertimbangan dan masukan dengan harapan bahwa dengan usaha kerajinan sapu serabut kelapa dapat meningkatkan tingkat kesejahteraan dan ekonomi masyarakat, adalah sebagai 
berikut: (1) Kerajinan sapu serabut kelapa harus menjadi produk unggulan untuk terus dikembangkan dan dilestarikan dengan memperhatikan kualitas dan kuantitas dari produk tersebut. (2) Pengadaan bahan baku serabut kelapa harus membanngun komonikasi yang inten dengan pengusaha yang berhubungan dengan bahan baku seperti pengusaha kelapa. (3) Mengupayakan dedanda (pegangan sapu) yang terbuat dari plastik tidak lagi dari kayu, guna mengurangi terjadinya dampak lingkungan seperti penebangan pohon secara liar. (4) Menggunakan mesin Dalam proses produksi agar dapat membantu mempercepat dan mempermudah proses produksi sapu serabut kelapa. (5) Dalam proses distribusi hasil produksi, hendaknya menggunakan system satu pintu, sehingga dapat dengan mudah menilai dan mengevaluasi soal harga sapu serabut kelapa di pasaran. (6) Untuk menjaga eksistensi dan keberlanjutan usaha kerajinan sapu serabut kelapa hendaknya membentuk lembaga/unit kerja kelomnpok seperti Unit Desa/Koperasi sehingga ada yang selalu aktif mengawasi, mengevaluasi serta memprediksi soal kualitas dan kuantitas hasil produksi. (7) Untuk meningkatkan daya guna dan daya saing dalam dunia pasar, pengerajin harus berani dan mampu mebuat produk lain selain sapu dari bahan baku yang sama. (8) Untuk Pemerintah Desa, hendaknya didorong dan dipasilitasi dalam rangka menjamin dan melestarikan keberlanjutan usaha ekonomi kerakyatan berupa kerajinan sapu serabut kelapa, sebagai suatu upaya untuk mendorong tingkat kesejahteraan masyarakat dan peningkatan ekonomi masyarakat. (9) Bagi peneliti selanjutnya, hendaknya meneliti tentang faktor apa saja yang menyebabkan tingkat ekonomi masyarakat sebagai pengerajin sapu serabut kelapa sangat rendah bahkan hanya 6\%, sementara 75-80\% masyarakat memilih menjadi penegerajin sapu serabut kelapa bertahun-tahun lamanya hingga saat ini.

\section{DAFTAR PUSTAKA}

Arikunto, S. 2002. Prosedur Penelitian. PT. Rineka Cipta : Jakarta

Alwi, H. 2005. Kamus Besar Bahasa Indonesia Edisi Ketiga. Balai Pustaka : Jakarta

Kotler, Philip. 2000. Menejemen Pemasaran di Indonesia. Salemba Empat : Jakarta

Kantor Desa Telaga Waru. 2016. Profil Desa Telaga Waru Tahun 2016. Telaga 
Riswanto, Nirwana. Analisis pengaruh Usaha Kerajinan Serabut Kelapa dengan Peniingkatan ekonomi...

Waru

Riduwan, 2005, Metode dan Tehnik Menyusun Tesis, CV. Alfabeta, Bandung Sugiyono. 2001. Metodelogi Penelitian. CV. Alfabeta : Bandung

Sugiyono. 2004. Metode Penelitian Bisnis. CV. Alfabeta : Bandung. Program SPSS. 15.0 